\title{
Cocaine Potency at the Dopamine Transporter Tracks Discrete Motivational States During Cocaine Self-Administration
}

\author{
Cody A Siciliano' and Sara R Jones*,I \\ 'Department of Physiology and Pharmacology, Wake Forest School of Medicine, Winston-Salem, NC, USA
}

\begin{abstract}
Although the dopamine transporter (DAT) is the primary site of action for cocaine, and the dopamine system is known to mediate the reinforcing effects of cocaine, the dopaminergic variations underlying individual differences in cocaine self-administration behaviors are not fully understood. Recent advances in the application of economic principles to operant tasks in rodents have allowed for the within-subject, within-session determination of both consummatory and appetitive responding for reinforcers. Here we combined a behavioral economics approach with cocaine self-administration and ex vivo voltammetric recording of dopamine signaling in the core of the nucleus accumbens of rats to determine the relationship between dopamine signaling and discrete aspects of cocaine taking and seeking. We found neither dopamine release or uptake tracked individual differences in cocaine consumption or the reinforcing efficacy of cocaine. Cocaine potency at the DAT was correlated with reinforcing efficacy, but was not related to cocaine consumption. Further, we introduce a novel analysis that determines perseverative responding within the same procedure, and find that cocaine potency at the DAT also tracks differences in perseverative responding. Together, we demonstrate that cocaine effects at the DAT determine the reinforcing efficacy of cocaine, and perseverative responding for sub-threshold doses of cocaine that do not maintain responding when presented in isolation. Surprisingly, we find that variations in cocaine potency do not account for differences in cocaine consumption, suggesting that satiation for cocaine is determined by other targets or mechanisms. Finally, we outline a novel approach for relating drug-target interactions and potency to discrete motivational states during a single self-administration session.

Neuropsychopharmacology (2017) 42, I893-1904; doi: 10.1038/npp.2017.24; published online I5 March 2017
\end{abstract}

\section{INTRODUCTION}

Several decades of literature have highlighted the integral importance of the dopamine system in mediating motivated behaviors, and the reinforcing effects of cocaine. In humans, cocaine occupancy of the dopamine transporter (DAT) correlates with the self-reported 'high' experienced by cocaine users (Volkow et al, 1997). In animal models, pharmacological and ablation studies have demonstrated that dopamine signaling in the nucleus accumbens (NAc) mediates the reinforcing and discriminative stimulus effects of cocaine (Roberts et al, 1977; Ritz et al, 1987; Wood and Emmett-Oglesby, 1989; Callahan et al, 1997). Further, genetic mutations of the DAT which produce cocaine insensitivity have shown that cocaine actions at the DAT are necessary for cocaine self-administration as well as conditioned place preference for cocaine (Chen et al, 2006; Thomsen et al, 2009). Although it is clear that the dopamine system is critically involved in cocaine self-administration, the contribution of specific aspects of dopamine

\footnotetext{
*Correspondence: Dr SR Jones, Department of Physiology and Pharmacology, Wake Forest School of Medicine, Medical Center Blvd., Winston-Salem, NC 27I57, USA, Tel: 336 7I 6 8533, Fax: 336 7I 6 850I, E-mail: srjones@wakehealth.edu

Received 30 September 2016; revised 23 December 2016; accepted 12 January 2017; accepted article preview online 31 January 2017
}

neurotransmission to discrete types of addictive behaviors remains an area of great interest.

Recently, preclinical drug self-administration models have been developed to measure economic demand for reinforcers, such as cocaine. Shifting the availability of cocaine, by changing the amount received per response, and recording consumption of cocaine, allows for an assessment of the interplay between supply and demand (Oleson et al, 2011; Oleson and Roberts, 2009; Oleson and Roberts, 2012; Bentzley et al, 2013). From these data, we can determine cocaine consumption $\left(\mathrm{Q}_{0}\right)$, and reinforcing efficacy of cocaine $\left(P_{\max }\right)$, within a single animal, in a single $110 \mathrm{~min}$ session. Here, we combined this approach with ex vivo fastscan cyclic voltammetry (FSCV), which provides functional measures of dopamine signaling, presynaptic receptor effects on dopamine transmission, and cocaine potency at the DAT (Ferris et al, 2013). Combining voltammetric measures with these behavioral approaches allows for comparison of specific aspects of dopamine signaling to discrete facets of cocaine taking behaviors. Cocaine-induced increases in extracellular dopamine levels, and the resulting behavior, are a complex interaction between its direct actions at the DAT and recruitment of many other regulators of dopamine neurotransmission. For example, dopamine autoreceptors and $\kappa$-opioid receptors both act to regulate presynaptic dopamine transmission and can alter cocaine potency (McGinnis et al, 2016; Ehrich et al, 2014). Given that the 
DAT mediates the subjective (Volkow et al, 1997) and discriminative stimulus (Cunningham and Callahan, 1991; Melia and Spealman, 1991) effects of cocaine, and is necessary for self-administration of the drug (Thomsen et al, 2009), we hypothesized that cocaine potency at the DAT would track both cocaine consumption $\left(\mathrm{Q}_{0}\right)$ and motivation $\left(P_{\max }\right)$.

Following completion of the behavioral economics procedure, we used FSCV to determine dopamine release, dopamine uptake, cocaine potency at the DAT, and the ability of $\kappa$-opioid receptors and D2/D3 dopamine autoreceptors to regulate dopamine release. Consistent with our hypothesis, we found that cocaine potency at the DAT tracked individual differences in $P_{\max }$, while all other measures did not correlate with $P_{\max }$. In contrast to our hypothesis, we found no relationship between cocaine potency and $\mathrm{Q}_{0}$. Finally, we outline a novel analysis of the behavioral economics procedure to measure perseverative responding for sub-threshold doses of cocaine (ie, doses of cocaine that do not maintain responding when presented in isolation), and show that cocaine potency also tracks perseverative responding. Together, these data show that cocaine potency at the DAT controls the motivational aspects of cocaine, but that cocaine consumption and satiety are likely controlled by other mechanisms or transmitter systems. The new methods outlined here provide a powerful a

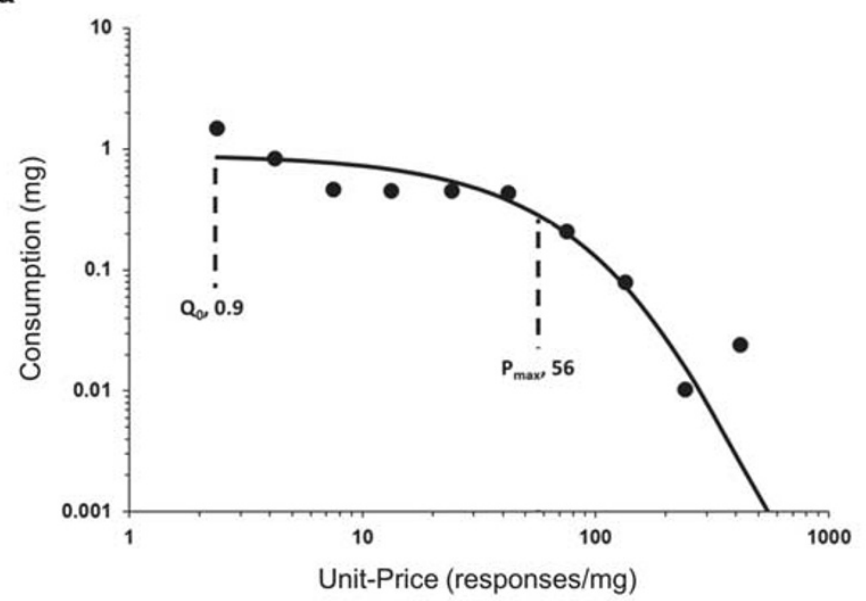

C

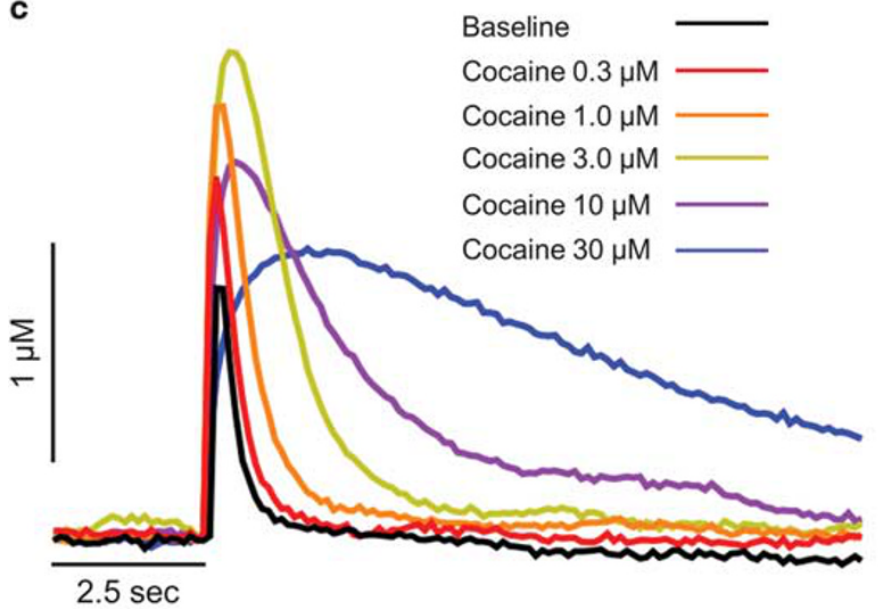

b

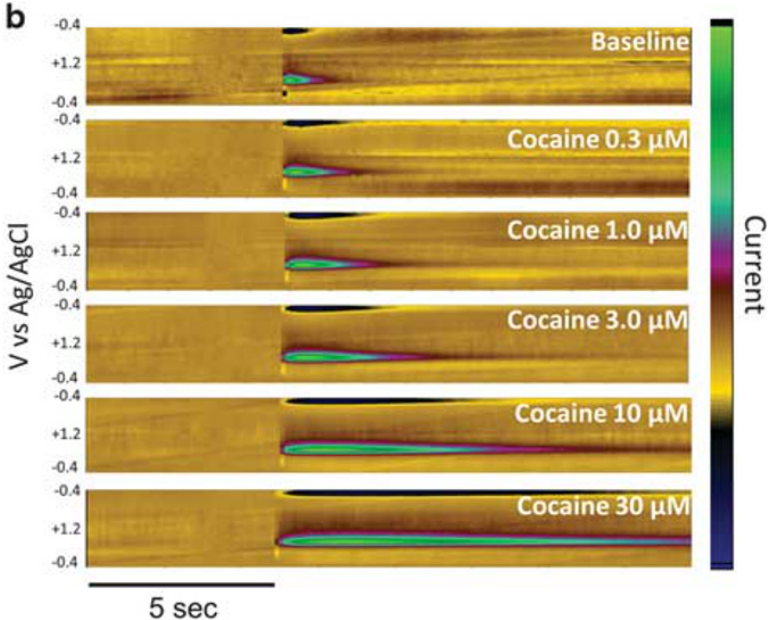

d

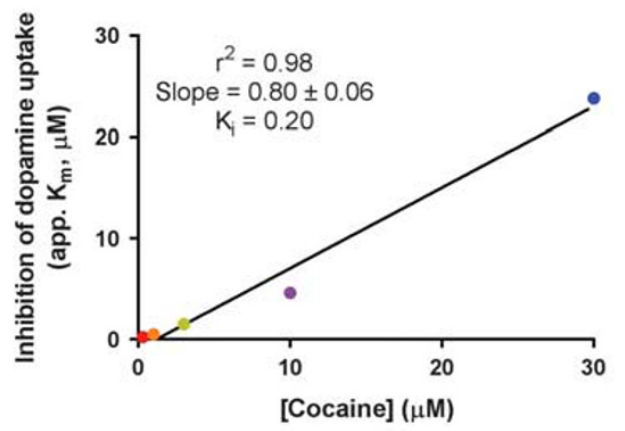

e

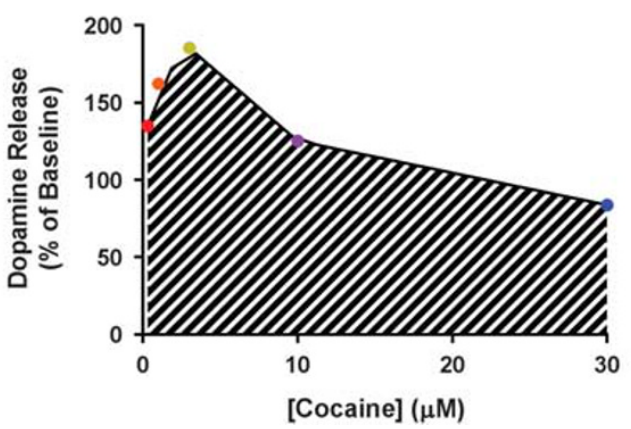

Figure I Cocaine consumption, motivation, and cocaine effects at the DAT assessed with behavioral economics and voltammetry. (a) Representative demand curve. The threshold procedure allows for a within-subject within-session determination of cocaine consumption $\left(Q_{0}\right)$ and the reinforcing efficacy of cocaine $\left(P_{\max }\right)$. (b) Representative pseudo-color plots showing the presence of dopamine indicated by changes in current ( $z$-axis) occurring at the oxidation and reduction potentials for dopamine (y-axis) over time (x-axis). Plots show baseline dopamine release and uptake (top) and across increasing concentrations of cocaine $(0.3-30 \mu \mathrm{M})$. (c) Representative traces showing increased uptake inhibition across increasing concentrations of cocaine. (d) The inhibitory constant $\mathrm{K}_{i}$ was calculated for each animal from the linear concentration-response curve of cocaine effects on dopamine uptake. (e) Cocaine's effects on dopamine release were assessed by plotting the percent change in dopamine release across concentration and calculating the area under the curve for each animal. 
approach to relating receptor signaling and drug potencies to discrete aspects of motivated behavior.

\section{MATERIALS AND METHODS}

\section{Animals}

Male Sprague-Dawley rats (350-400 g; Harlan Laboratories, Frederick, Maryland), maintained on a $12: 12 \mathrm{~h}$ reverse light/ dark cycle ( 0300 hours lights off; 0300 hours lights on) with food and water ad libitum. All animals were maintained according to the National Institutes of Health guidelines in Association for Assessment and Accreditation of Laboratory Animal Care accredited facilities. The experimental protocol was approved by the Institutional Animal Care and Use Committee at Wake Forest School of Medicine.

\section{Self-Administration Surgery and Training}

Rats were anesthetized and implanted with chronic indwelling jugular catheters as previously described (Siciliano et al, 2015a). Animals were singly housed, and all sessions took place in the home cage during the active/dark cycle (09001500 hours). After a 2-day recovery period, animals underwent a training paradigm within which animals were given access on a fixed ratio one (FR1) schedule to a cocaine-paired lever, which, upon responding, initiated an intravenous injection of cocaine $(0.75 \mathrm{mg} / \mathrm{kg}$, infused over $4 \mathrm{~s})$. After each response/infusion, the lever was retracted and a stimulus light was illuminated for a $20 \mathrm{~s}$ timeout period. Training sessions were terminated after a maximum of 20 infusions or $6 \mathrm{~h}$, whichever occurred first. Acquisition occurred when an animal responded for 20 injections for two consecutive days and a stable pattern of infusion intervals was present.

\section{Threshold Procedure}

Following acquisition of cocaine maintained responding, the threshold procedure was used to determine individual differences in cocaine consumption and motivation. A total of 14 animals performed the threshold procedure, and were used for subsequent voltammetry experiments (below). The threshold procedure is a behavioral economics approach to assessing drug taking/seeking and reinforcing efficacy. The threshold procedure consists of giving rats access to a descending series of 11 unit doses of cocaine $(421,237,133$, $75,41,24,13,7.5,4.1,2.4$, and $1.3 \mu$ g per injection) available on an FR1 schedule of reinforcement. Each dose is available for $10 \mathrm{~min}$, with each bin presented consecutively across the 110-min session. During this time the lever is never retracted, and the only timeout periods occur during each infusion. Completion of the procedure produces a withinsession demand curve, depicted in Figure 1a. During the initial bins of the procedure, when the dose is high, the animal is able to obtain a preferred level of cocaine intake with minimal responding. As the dose is lowered across bins, the animal must increase responding to maintain consistent intake, until the dose becomes low enough that preferred levels of cocaine cannot be maintained and responding decreases. Shifts in responding across the demand curve can be analyzed using behavioral economics principles, as described below. Responding during the first bin of the procedure is considered to reflect a loading phase and is not included in the analyses.

Behavioral economic analysis was used to determine the parameters of maximal price paid $\left(P_{\max }\right)$ and consumption at a minimally constraining price $\left(\mathrm{Q}_{0}\right)$, as described previously (Oleson et al, 2011; Oleson and Roberts, 2009; Oleson and Roberts, 2012; Bentzley et al, 2013). Briefly, $P_{\max }$ and $\mathrm{Q}_{0}$ values were derived mathematically using a demand curve. Demand curves were generated by curve-fitting individual animals' intake using an equation: $\log (\mathrm{Q})=\log \left(\mathrm{Q}_{0}\right)+\mathrm{k} \times(\mathrm{e}-$ $\alpha \times \mathrm{Q}_{0} \times \mathrm{C}-1$ ) (Hursh and Silberberg, 2008; Christensen et al, 2008). In this equation, $P_{\max }$ was determined to be the unit price at which the first derivative point slope of the function $=-1$ (Hursh and Winger, 1995). The value $k$ was set to 2 for all animals, whereas $\mathrm{Q}_{0}$ and $\alpha$, which represent the acceleration of the function in response to changing price, were estimated to achieve best fit (Hursh and Silberberg, 2008; Christensen et al, 2008). These measures are explained in detail below.

\section{$\mathbf{Q}_{0}$}

$\mathrm{Q}_{0}$ is a measure of the animals' preferred level of cocaine consumption. This can be measured when the dose is high and cocaine is available at low effort, or a minimally constraining price. This preferred level of consumption is established in the early bins of the threshold procedure.

\section{$\boldsymbol{P}_{\max }$}

Price is expressed as the responses emitted to obtain $1 \mathrm{mg}$ of cocaine, thus as the dose is decreased in each consecutive bin of the threshold procedure, price increases. As the session progresses, animals must increase responding on the active lever in order to maintain stable intake. $P_{\max }$ is the price at which the animal no longer emits enough responses to maintain intake and consumptions decreases. Thus, animals with higher $P_{\max }$ will increase responding to maintain cocaine levels farther into the demand curve; in other words they will pay a higher price for cocaine. Previous work has demonstrated that $P_{\max }$ is highly correlated with break points on a progressive ratio schedule of reinforcement, confirming that the threshold procedure accurately assesses reinforcing efficacy (Oleson et al, 2011). To remove any possible contribution of variations in $\mathrm{Q}_{0}$ to $P_{\max }$ values, each animals' $P_{\max }$ was normalized to $\mathrm{Q}_{0}$.

\section{Brain Cocaine Concentrations}

Brain-cocaine concentrations were estimated using equations employed by Pan et al (1991). The equation used was

$$
c=\frac{d k}{v(\alpha-\beta)}\left(e^{-\beta t}-e^{-\alpha t}\right)
$$

which calculates the brain-cocaine concentration in the brain compartment at time $t$. The variables account for the dose of cocaine $(d)$, the transfer of drug between the blood and brain compartments $\left(k=0.233 \mathrm{~min}^{-1}\right)$, the apparent volume of the brain compartment $\left(v=0.15 \mathrm{LKg}^{-1}\right)$, and the removal of cocaine from the system via redistribution $\left(\alpha=0.642 \mathrm{~min}^{-1}\right)$ and elimination $\left(\beta=0.097 \mathrm{~min}^{-1}\right)$. This equation has been widely used to correlate estimated brain-cocaine levels with 
behavioral (Ahmed and Koob, 2005; Zimmer et al, 2012), electrophysiological (Peoples et al, 2007; Peoples et al, 2004), microdialysis (Wise et al, 1995), and voltammetric (Hermans et al, 2008; Stuber et al, 2005a; Stuber et al, 2005b; Calipari et al, 2014) measures.

\section{Ex Vivo Voltammetry}

Animals were killed for FSCV experiments the morning following the final threshold session (approximately $18 \mathrm{~h}$ ), when no drug was present. FSCV was used to characterize presynaptic dopamine system kinetics, and the ability of cocaine to inhibit dopamine uptake in the NAc core. As previously described (Siciliano et al, 2014a), a vibrating tissue slicer was used to prepare $400 \mu \mathrm{m}$ thick coronal brain sections containing the NAc core. The tissue was immersed in oxygenated artificial cerebrospinal fluid (aCSF) containing (in $\mathrm{mM}$ ): $\mathrm{NaCl}$ (126), $\mathrm{KCl}(2.5), \mathrm{NaH}_{2} \mathrm{PO}_{4}$ (1.2), $\mathrm{CaCl}_{2}$ (2.4), $\mathrm{MgCl}_{2}$ (1.2), $\mathrm{NaHCO}_{3}$ (25), glucose (11), L-ascorbic acid (0.4) and $\mathrm{pH}$ was adjusted to 7.4. Once sliced, the tissue was transferred to the testing chambers containing bath aCSF $\left(32^{\circ} \mathrm{C}\right)$, which flowed at $2 \mathrm{ml} / \mathrm{min}$. A carbon fiber microelectrode (100-200 $\mu \mathrm{M}$ length, $7 \mu \mathrm{M}$ diameter) and bipolar stimulating electrode were placed into the core of the NAc, which was selected because of its role in the reinforcing and rewarding actions of cocaine. Dopamine release was evoked by a single electrical pulse $(350 \mu \mathrm{A}, 4 \mathrm{~ms}$, monophasic) applied to the tissue every $3 \mathrm{~min}$. Extracellular dopamine was recorded by applying a triangular waveform $(-0.4$ to +1.2 to $-0.4 \mathrm{~V}$ vs $\mathrm{Ag} / \mathrm{AgCl}, 400 \mathrm{~V} / \mathrm{s}$ ). Once the extracellular dopamine response was stable, cocaine concentrations (0.3-30 $\mu \mathrm{M})$ were applied in ascending order to the brain slice. In a randomly chosen subset of animals, multiple brain slices were procured for $\kappa$-opioid and D2 autoreceptor experiments. In these cases, five ascending concentrations of quinpirole $(3-300 \mathrm{nM})$ or U50,488 $(0.03-3 \mu \mathrm{M})$ were applied to separate slices that were run concomitantly on different rigs. No single slice was exposed to more than one drug.

\section{$K_{\mathbf{i}}$ Values}

As described previously (Siciliano et al, 2014b), inhibition constants $\left(\mathrm{K}_{\mathrm{i}}\right)$ were calculated by the equation: $\left[\left(\mathrm{K}_{\mathrm{m}}\right) /(\mathrm{S})\right]$ where $K_{m}$ is equal to the $K_{m}$ of dopamine for the DAT, or $0.16 \mu \mathrm{M}$, and $\mathrm{S}$ is equal to the slope of the linear concentration-response regression for cocaine. The $\mathrm{K}_{\mathrm{i}}$, is reported in $\mu \mathrm{M}$ and is a measure of the cocaine concentration that is necessary to decrease the rate of dopamine-DAT interactions to $50 \%$ of their uninhibited rate.

\section{Data Analysis}

For all analysis of FSCV data Demon Voltammetry and Analysis software was used (Yorgason et al, 2011). To evaluate dopamine kinetics and drug potency, evoked levels of dopamine were modeled using Michaelis-Menten kinetics. Recording electrodes were calibrated by recording responses (in electrical current; $\mathrm{nA}$ ) to a known concentration of dopamine $(3 \mu \mathrm{M})$ using a flow-injection system. This was used to convert electrical current to dopamine concentration. For cocaine concentration-response curves, app. $K_{m}$, a measure of apparent affinity for the DAT, was used to determine changes in ability of the cocaine to inhibit dopamine uptake. As app. $\mathrm{K}_{\mathrm{m}}$ increases, uptake inhibition increases, and changes in drug potency are seen as shifts in the curve.

For experiments predicting cocaine effects on dopamine uptake, each animal's cocaine concentration-response curve was fit with a linear regression. The resulting equation $(y=m x+b)$ was used to predict effects of cocaine on dopamine uptake where estimated brain cocaine concentration equals $x$, and the resulting $y$ value was used for correlations with behavior. For predicting cocaine's effects on dopamine release, concentration-response curves for cocaine's effects on dopamine release for each animal were fit with a 40 segment spline point-to-point standard curve. Predicted values $y$ were then interpolated from $x$ values corresponding to estimated peak brain cocaine concentrations from each bin of the behavioral procedure.

\section{Statistics}

Graph Pad Prism (version 6, La Jolla, CA, USA) was used to statistically analyze data sets and create graphs. Pearson's correlation coefficient was used to measure the strength of correlation. In some cases, when significant correlation were found, a tertiary split of the data was performed based on $\mathrm{K}_{\mathrm{i}}$ values for each animal; the lowest third of $K_{i}$ values are referred to as a 'high potency' group while the highest third of $\mathrm{K}_{\mathrm{i}}$ were referred to as 'low potency' animals. Behavioral data from high- and low-potency animals were compared using a two-tailed unpaired Student's $t$-test. All $p$ values of $<0.05$ were considered to be statistically significant.

\section{RESULTS}

Behavioral Economics and Voltammetry Allow WithinSubject Determination of Cocaine Consumption, Motivation, and Dopamine Terminal Function

Animals performed the within-session threshold procedure to generate demand curves, which were used to determine preferred levels of cocaine consumption $\left(\mathrm{Q}_{0}\right)$, and motivation to administer cocaine $\left(P_{\max }\right)$ (Figure 1a). Following completion of the threshold procedure, animals were sacrificed for ex vivo voltammetric recordings to determine dopamine release and uptake kinetics in the NAc core (Table 1). Cocaine has two distinct actions on dopamine neurotransmission, one is to inhibit the uptake of dopamine,

Table I Averages and Error for Each Behavioral and Neurochemical Measure Reported

\begin{tabular}{lc}
\hline Measure & Mean \pm SEM \\
\hline$Q_{0}(\mathrm{mg})$ & $0.38 \pm 0.04$ \\
$P_{\max }($ responses $/ \mathrm{mg})$ & $83.89 \pm 14.43$ \\
Dopamine Release $(\mu M)$ & $0.81 \pm 0.09$ \\
$V_{\max }(\mu M / S)$ & $2.68 \pm 0.20$ \\
$K_{i}$ Cocaine $(\mu M)$ & $0.4 I \pm 0.04$ \\
\hline
\end{tabular}

Values were derived from 14 animals. 


\section{Dopamine Release}
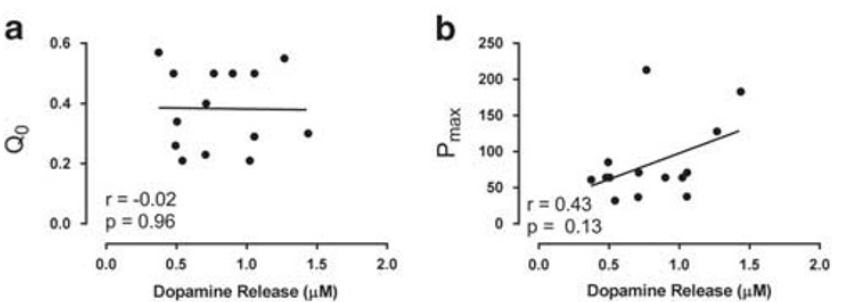

Dopamine Uptake
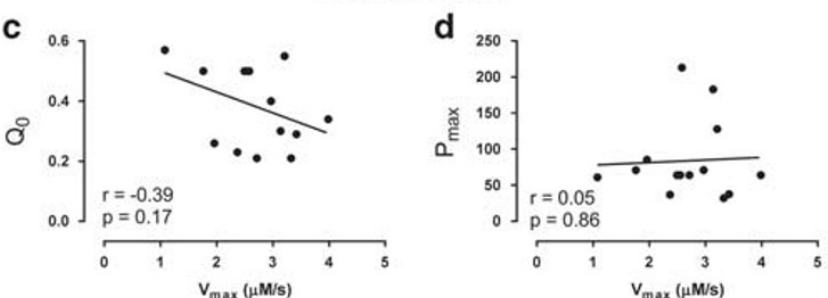

Cocaine Effects on Dopamine Release
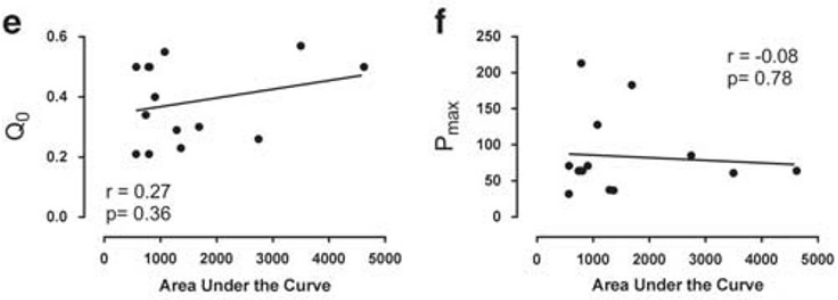

Cocaine-Induced Uptake Inhibition
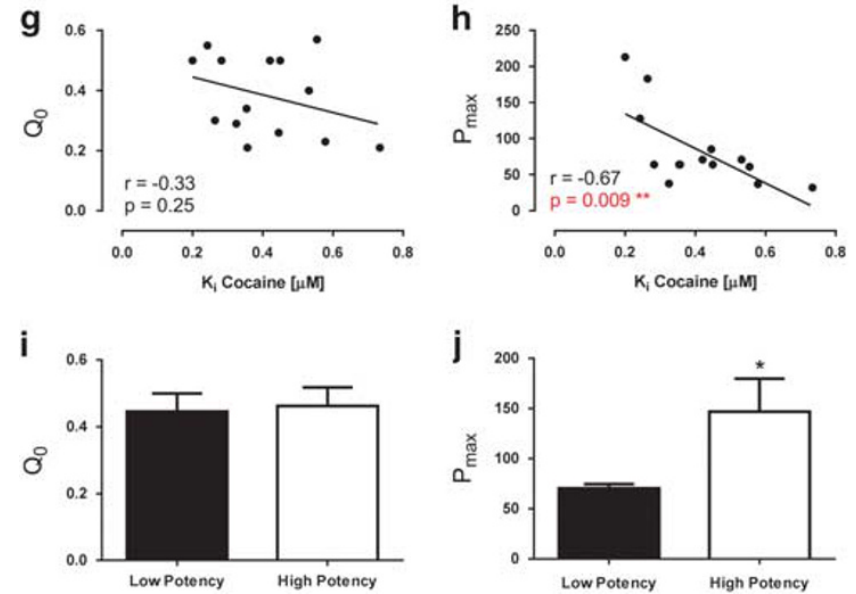

Figure 2 Cocaine potency at the DAT is correlated with reinforcing efficacy of cocaine, but not cocaine consumption. Dopamine release magnitude does not correlate with $Q_{0}$ (a) or $P_{\max }$ (b) Maximal rate of dopamine uptake $\left(V_{\max }\right)$ does not correlate with $Q_{0}$ (c) or $P_{\max }(\mathrm{d})$. Total area under the curve for cocaine effects on dopamine release across concentrations does not correlate with $Q_{0}(e)$ or $P_{\max }(f)$. Although cocaine potency $\left(K_{i}\right)$ does not correlate with $Q_{0}(g)$, there was a negative correlation between $K_{i}$ and $P_{\max }(h)$. (i) Tertiary split of the data based on $K_{i}$ revealed that $Q_{0}$ does not differ between low ( $n=5$ ) and high $(n=4)$ potency animals. (j) $P_{\max }$ is increased in animals with high cocaine potency. ${ }^{*} p<0.05$; $* * p<0.0 \mid$. $N=\mid 4$.

and the other is to alter dopamine release (Venton et al, 2006; Siciliano et al, 2015b; Hoffman et al, 2016). We bath applied ascending concentrations of cocaine to the slice, which resulted in concentration-dependent changes in dopamine uptake and dopamine release (Figure $1 \mathrm{~b}$ and $\mathrm{c}$ ). By measuring cocaine-induced inhibition of dopamine uptake across a concentration-response curve we were able to calculate the inhibitory constant $K_{i}$ (Figure $1 d$ ). $K_{i}$ is a measure of the amount of cocaine needed to inhibit dopamine uptake to $50 \%$ of its uninhibited value, thus low
$\mathrm{K}_{\mathrm{i}}$ values for cocaine are analogous to high cocaine potency. Further, we assessed cocaine effects on dopamine release across concentrations and calculated an area under the curve score, generated from the entire concentration-response curve, for each animal (Figure 1e). Group means for behavioral and voltammetric measures recorded are reported in Table 1. Group data for cocaine self-administration acquisition data, and concentration-response and demand curves are depicted in Supplementary Figure 1. 


\section{Cocaine Potency at the DAT Predicts $\boldsymbol{P}_{\max }$, But Not $\mathbf{Q}_{0}$}

Having determined cocaine taking and seeking behaviors and dopamine system function in a within-subject fashion, we sought to determine if variations in dopamine signaling were related to individual differences in cocaine consumption $\left(\mathrm{Q}_{0}\right)$ and motivation $\left(P_{\max }\right)$. We found that stimulated dopamine release in the absence of cocaine was not related to $\mathrm{Q}_{0}$ or $P_{\max }$ (Figure $2 \mathrm{a}$ and $\mathrm{b}$ ). Further, there was no relation between the maximal rate of dopamine uptake and either measure of cocaine taking (Figure $2 \mathrm{c}$ and $\mathrm{d}$ ). In addition, we found no relationship between area under the curve for cocaine's actions across concentrations on dopamine release and $\mathrm{Q}_{0}$ or $P_{\max }$ (Figure 2e and f). However, we found that the $\mathrm{K}_{\mathrm{i}}$ for cocaine was negatively correlated with $P_{\max }(r=-0.67$, $p=0.009$ ), but not $Q_{0}$, suggesting that the ability of cocaine to inhibit the DAT drives demand for cocaine, but not cocaine consumption (Figure $2 \mathrm{~g}$ and $\mathrm{h}$ ). Indeed, following a tertiary split based on $K_{i}$ values, we found no differences in $\mathrm{Q}_{0}$ between groups, but $P_{\max }$ was elevated in high potency animals $\left(t_{7}=2.62, p=0.03\right.$ ) (Figure $2 \mathrm{i}$ and $\mathrm{j}$ ).

To determine if presynaptic regulators of dopamine release may also be contributing to differences in cocaine consumption and motivation, we probed the sensitivity of the $\kappa$-opioid receptor and D2/D3 dopamine autoreceptors. Concentrationresponse curves of the selective $\kappa$-opioid receptor agonist $\mathrm{U} 50,488$ revealed no relationship between the $\mathrm{IC}_{50}$ of $\mathrm{U} 50,488$ on dopamine release and $\mathrm{Q}_{0}$ (Supplementary Figure S2A) or $P_{\max }$ (Supplementary Figure S2B). Similarly, concentrationresponse curves for quinpirole, a D2/D3 dopamine receptor agonist, revealed no relationship between autoreceptor sensitivity and $\mathrm{Q}_{0}$ (Supplementary Figure S2C) or $P_{\max }$ (Supplementary Figure S1D). Finally, to ensure that none of the behavioral measures tested were influenced by animal weight, we correlated weight at the start of the experiment with $\mathrm{Q}_{0}$ (Supplementary Figure S3A) or $P_{\max }$ (Supplementary Figure $\mathrm{S} 3 \mathrm{~B}$ ) and found that were was no relationship in either case.

\section{The Threshold Procedure Allows Within-Session Determination of Discrete Motivational States}

Having found that cocaine potency at the DAT appears to be a determining factor in the maximal price that an animal is willing to pay for cocaine, we next sought to determine if cocaine actions at the DAT were also controlling the reinforcing aspects of cocaine during discrete motivational states. To address this question, we split the threshold session into three epochs: the consumption epoch, which occurs when the cocaine price is low, the reinforcing efficacy epoch which occurs around the point when consumption drops, and the perseverative epoch, which occurs at doses of cocaine that are not reinforcing in isolation (Figure 3a). Perseverative responding is typically defined as the continuation of previously appropriate behavioral action which may be maladaptive (Hotz and Helm-Estabrooks, 1995) and is traditionally measured in cocaine self-administration studies by removing or decreasing the reinforcer at some point during the session (Bock et al, 2013). Rats do not selfadminister doses below $8 \mu \mathrm{g}$ per infusion and only $50 \%$ of rats will self-administer doses of $16.6 \mu \mathrm{g}$ per infusion (ZittelLazarini et al, 2007). Thus responding during bins below these doses, and after preferred levels of consumption are no longer maintained, represents perseverative responding for non-reinforcing doses of cocaine.

To determine if these epochs are indicative of dissociable phenomenon, we correlated total responses during each epoch. We found that responding during the consumption epoch did not correlate with responding during either the efficacy (Figure 3b) or perseverative epoch (Figure 3c) demonstrating that we can measure these concepts as discrete behaviors. We found that there was a trend towards a correlation between responding during the efficacy and perseverative epochs, although this not did not reach statistical significance (Figure 3d). Further, cocaine intake during the perseverative epoch was greatly reduced as compared with both the consumption and efficacy epochs $\left(\mathrm{F}_{(2,27)}=26.51, p<0.0001\right.$; Figure $\left.3 \mathrm{e}\right)$, as were brain cocaine concentrations $\left(F_{(2,27)}=15.85, p<0.0001\right)$ (Figure 3f). Thus, during this epoch, animals are responding for negligible amounts of cocaine, despite brain cocaine concentration dropping below its preferred level, confirming that perseverative responding is occurring.

\section{Cocaine-Induced Uptake Inhibition Predicts Responding for Cocaine During Discrete Motivational States}

To determine cocaine's actions at the DAT during each epoch, we modeled the peak brain cocaine concentration occurring during each $10 \mathrm{~min}$ interval (ie, at each dose of cocaine) of the threshold procedure (Figure $4 \mathrm{a}$ ). Using the modeled brain cocaine concentration we were then able to determine a predicted uptake inhibition using the linear regression equation generated from each animal's cocaine concentration-response curve as measured by voltammetry (Figure 4b). We found that, using the calculated uptake inhibition occurring during each dose of the threshold procedure (Figure 4c), we were not able to predict responding during the consumption epoch, further confirming that cocaine effects at the DAT are not the determining factor in consumption of cocaine (Figure 4d). However, uptake inhibition predicted responding during the reinforcing efficacy epoch, demonstrating that cocaine potency at the DAT is functionally related to the effort an animal is willing to exert to obtain cocaine $(r=0.37, p=0.0002)$ (Figure 4e). Finally, cocaine-induced inhibition of the DAT also predicted responding during the perseverative epoch, demonstrating that cocaine actions at the DAT also determine the extent to which an animal will perseverate for sub-threshold doses of cocaine (ie, doses of cocaine that do not maintain responding when presented in isolation) $(r=0.59, p=0.001)$ (Figure $4 \mathrm{f})$. A tertiary split of the data based on $K_{i}$ values confirmed that was no difference in responding between low and high potency animals in the consumption epoch, but that responding was greater in high potency animals in both the reinforcing $\left(t_{53}=3.72\right.$, $p=0.0005)$ and perseverative epochs $\left(t_{12}=2.60, p=0.02\right)$ (Figure $4 \mathrm{~g}-\mathrm{i}$ ). Further, to confirm that this analysis has utility over using brain cocaine concentrations alone to predict behavior, we correlated estimated brain cocaine concentrations and found that they did not predict responding during the consumption or efficacy epochs. We did find a positive correlation between brain cocaine concentrations and responding during the perseverative epoch $(r=0.48$, 


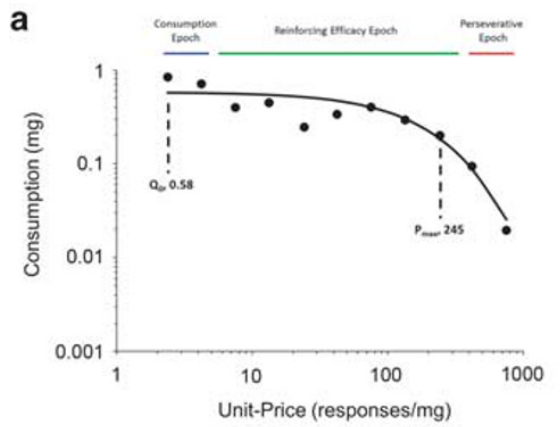

b

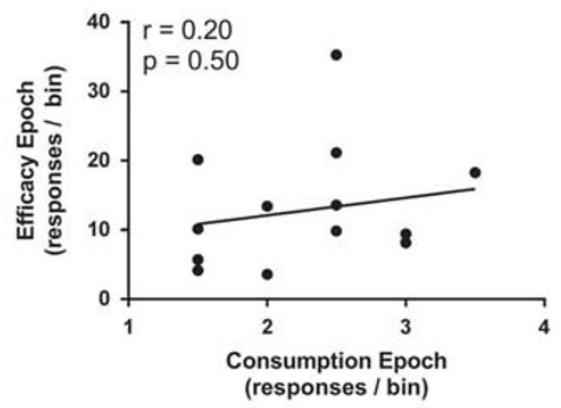

e

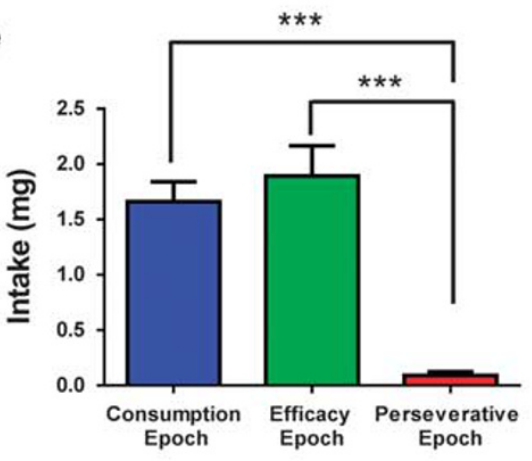

C

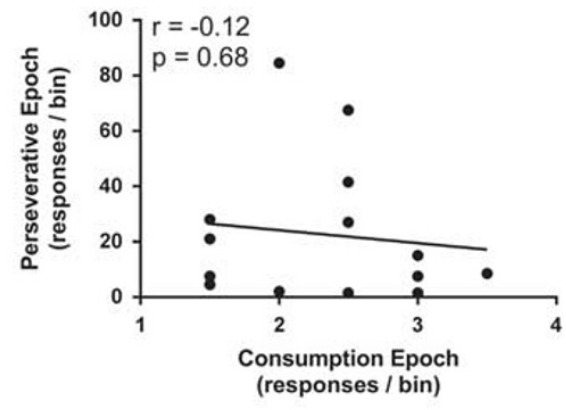

f

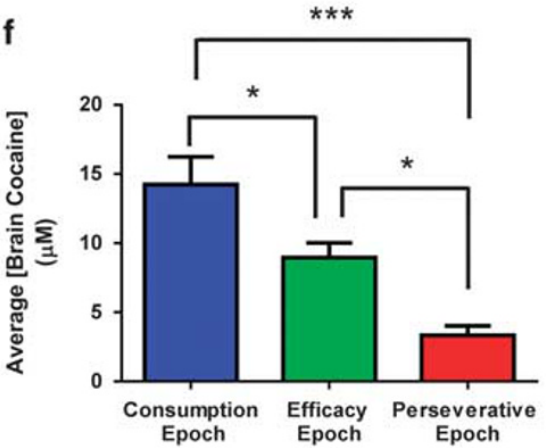

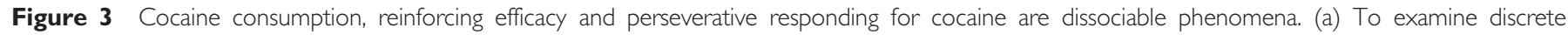

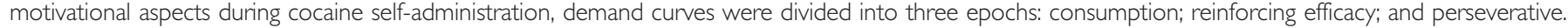

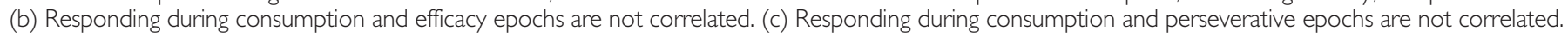

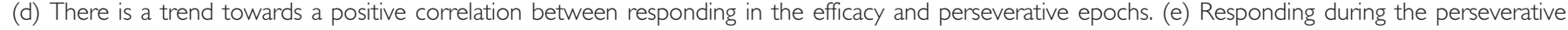

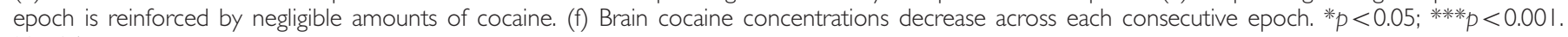
$N=14$.

$p=0.009$ ); however, less of the variance was explained than when cocaine's effects on uptake were accounted for $\left(r^{2}=0.23\right.$ vs $\left.r^{2}=0.35\right)$ (data not shown).

\section{Cocaine-Induced Changes in Dopamine Release Track Responding During the Efficacy Epoch}

Although, as shown above, we found no correlation between area under the curve for cocaine-induced changes in dopamine release, and $P_{\max }$ or $\mathrm{Q}_{0}$, this analysis is limited due to the fact that the effects of cocaine on dopamine release are non-linear and can differ in directionality depending on cocaine concentration. Thus, we next applied the approach outlined above, but plotted estimated brain cocaine concentration onto each animal's concentration-response curve for cocaine effects on dopamine release rather than uptake (Figure 5a). We found that, similar to uptake, our predicted measure of cocaine-induced change in dopamine release did not predict responding during the consumption epoch (Figure 5b). However, we did find a negative correlation between predicted cocaine-induced changes on dopamine release and responding during the perseverative epoch $(r=-0.23, p=0.03)$ (Figure 5c). Finally, we found no relationship between this measure and responding during the perseverative epoch. These findings demonstrate a link between cocaine's effects on dopamine release and responding during the efficacy epoch, and further support the utility of this methodological approach in regard to relating non-linear drug effects to behavior.

\section{DISCUSSION}

This work expands a growing literature using threshold procedures to dissect aspects of drug self-administration that were not addressable before the advent of this technique (Oleson et al, 2011; Oleson and Roberts, 2009; Oleson and Roberts, 2012; Calipari et al, 2015a; Bentzley et al, 2014; Porter-Stransky et al, 2015; Kawa et al, 2016). Here we show that individual differences in animals' motivation to selfadminister cocaine and to respond for cocaine at devalued doses can be partially accounted for by variations in cocaine potency. Surprisingly, we found that individual differences in cocaine consumption are not related to cocaine potency, or any other measure of dopamine terminal function examined here, including baseline dopamine release, dopamine uptake, and the sensitivity of $\mathrm{k}$-opioid receptors or D2/D3 autoreceptors in regulating dopamine release. Together, these data outline the dopaminergic variations underlying individual differences in addictive-like cocaine taking behaviors, and provide a novel analysis for within-subject examinations of discrete aspects of drug taking and seeking.

It is a fundamental goal of the behavioral pharmacology field to be able to compare behavioral outputs with drug actions at specific neuronal targets; here we outline novel 


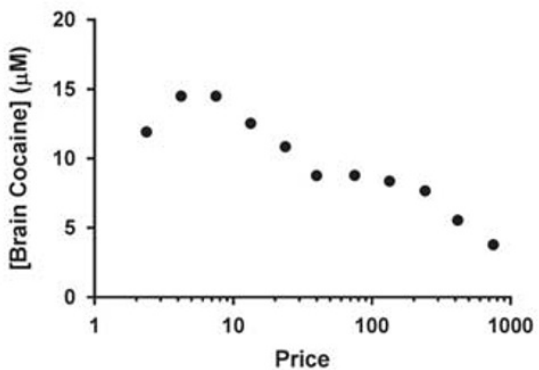

d

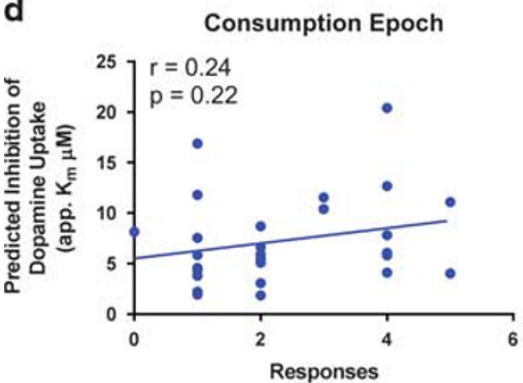

g

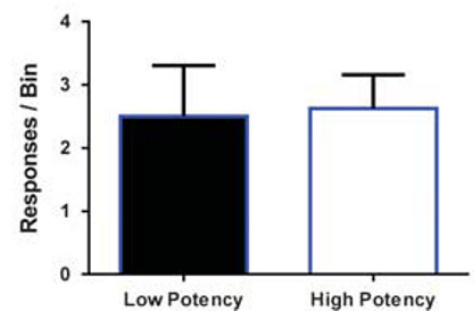

b

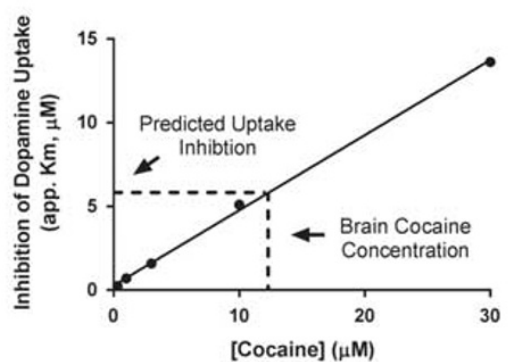

e

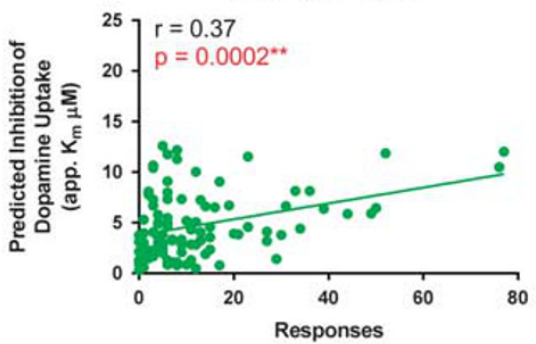

h

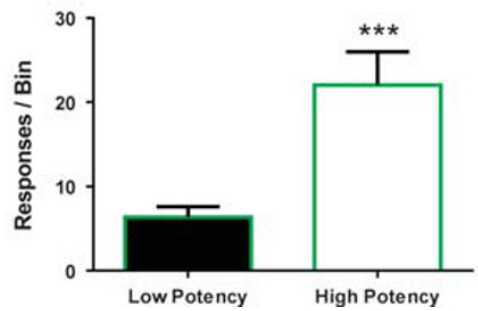

c

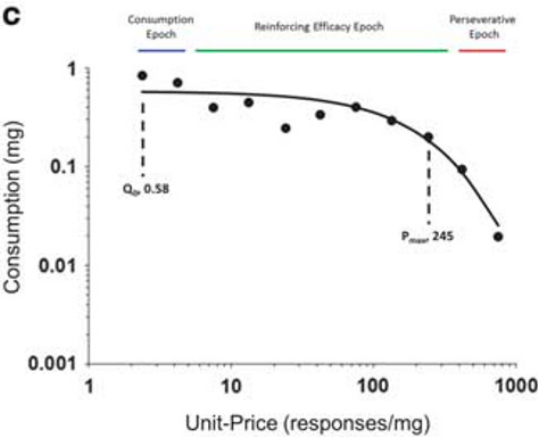

f

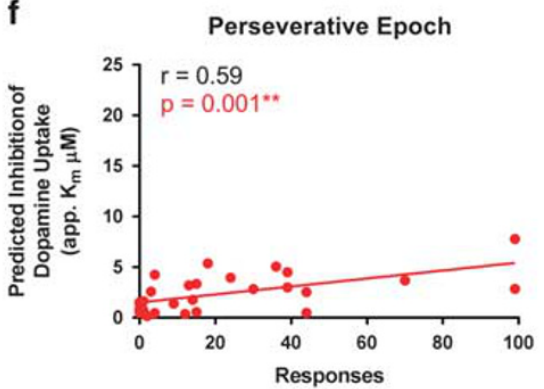

i

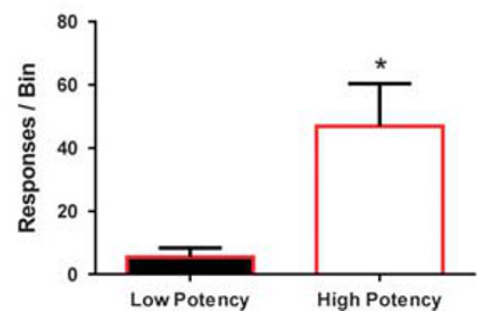

Figure 4 Cocaine-induced inhibition of the DAT determines discrete motivational states for cocaine. For each bin of the procedure, peak brain cocaine concentrations were determined (a). (b) Estimated peak brain cocaine concentration was substituted for $x$ in the linear regression equation generated from each animal's cocaine concentration-response curve to produce an estimated uptake inhibition, $y$. This resulted in a predicted uptake inhibition value occurring during each bin of the threshold procedure for each animal (c). (d) Uptake inhibition occurring during the consumption epoch was not related to the number of responses emitted. (e) Predicted uptake inhibition was correlated with responses during the reinforcing efficacy epoch. (f) There was a strong positive correlation between responses and predicted uptake inhibition during the perseverative epoch. $(\mathrm{g})$ Tertiary split of the data based on $\mathrm{K}_{i}$ values revealed no difference in responses per bin during the consumption epoch between high and low potency animals. Responses per bin were increased in high potency animals in both the efficacy (h) and perseverative (i) epochs. ${ }^{*} p<0.05$; $* * 0<0.01$, **** $p<0.001 . N=14$.

methods for determining the relationship between drug concentration, drug action and behavioral output in a within-subject, within-session fashion. Although there are many other approaches to measuring drug consumption and reinforcing efficacy in operant tasks, these two phenomenon are typically assessed during separate tasks (eg, fixed ratio or progressive ratio), which require many sessions across days (Richardson and Roberts, 1996) and can introduce confounds when performed within-subject. The threshold procedure circumvents these caveats by assessing reinforcing efficacy and consumption within a single session. Here we introduce multiple additional analyses that can be used with the threshold procedure. First, by splitting the demand curve into functional epochs, perseverative responding (that is, responding which occurs after the preferred consumption level has dropped) can be assessed. Although there are many advantages of using curve-fitting to model demand curves (Bentzley et al, 2013), these approaches act to limit the contribution of variability across cocaine doses. This variability, which occurs most robustly after brain concentrations have dropped below preferred levels, has typically been treated as problematic and thus analyses have been aimed at minimizing its contribution; however, as suggested by the experiments presented here, this variability may contain biologically relevant information. Further, by modeling brain levels of cocaine and mapping these values onto assessments of drug action in the same animal, the relationship between brain concentrations and cocaine effects can be directly compared with responding across these epochs. These approaches could be easily implemented with a wide range of pharmacological techniques to elucidate the relationship between the function of receptor/transporter systems or drug potencies and behavioral outputs for drug reinforcers. For example, by using classical GTP $\gamma \mathrm{S}$, electrophysiological, voltammetric or any other functional assay of drug effects, to generate concentration-response curves for drug actions at a specific target, and mapping estimated brain concentration values onto these curves, this method provides a means for relating drug effects to discrete behaviors. 

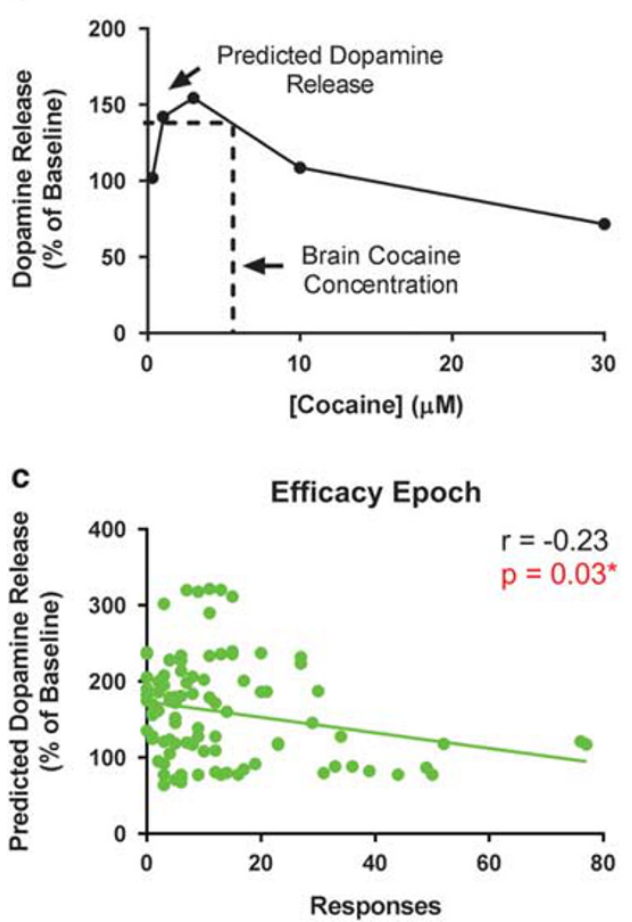

b
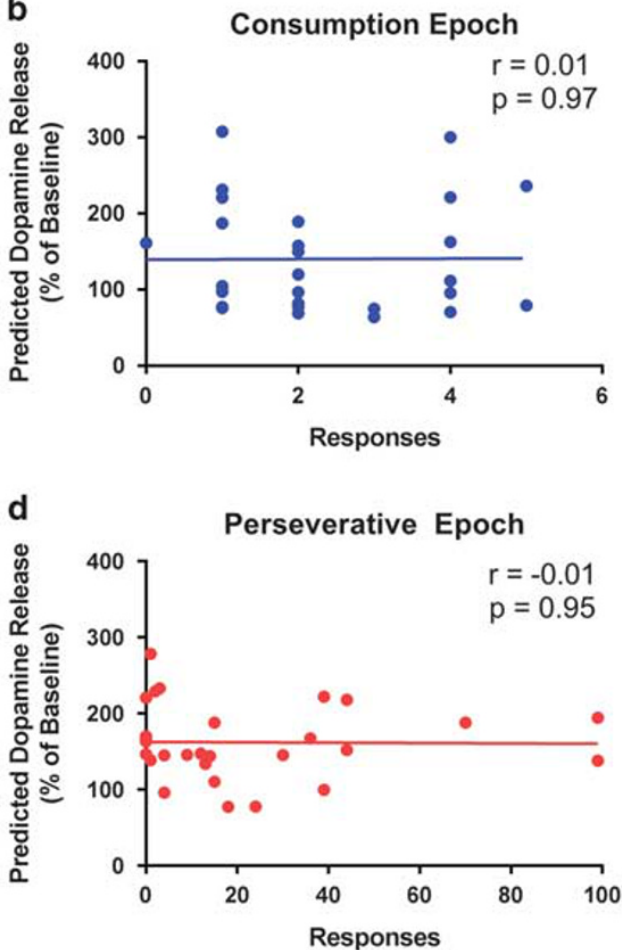

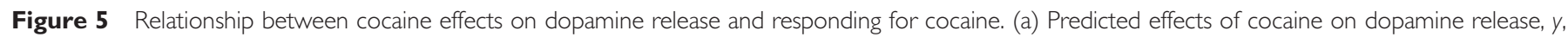

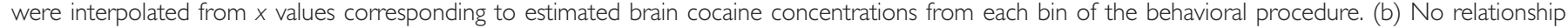

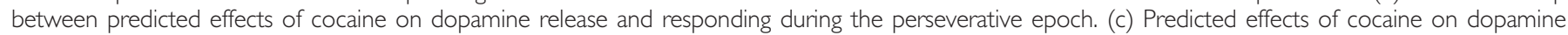

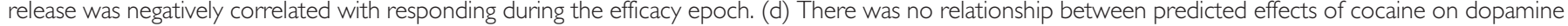
release and responding during the perseverative epoch. $N=14$.

Here, we use this method to show that variations in cocaine action at the DAT track individual differences in reinforcing efficacy of cocaine as well as perseverative responding for cocaine. It is well documented that under 'free-access' conditions (ie, low-effort schedules of reinforcement), animals and humans titrate their cocaine intake to establish and maintain a preferred brain/blood cocaine concentration (Tsibulsky and Norman, 1999; Paly et al, 1982). The upper limit of cocaine consumption, or satiety threshold, has been proposed to be directly related to accumbal dopamine levels (Pettit and Justice, 1989; Suto and Wise, 2011). Using the approaches outlined above we were able to assess the relationship between brain cocaine concentrations, cocaine potency at the DAT and responding during each epoch. Surprisingly, we found that cocaine potency at the DAT did not correlate with $\mathrm{Q}_{0}$, and predicted uptake inhibition was not related to lever presses during the consumption epoch. Thus, while cocaine action at the DAT is required for self-administration of cocaine (Thomsen et al, 2009), and gross manipulations of the dopamine system alter cocaine consumption/satiety thresholds (eg Suto and Wise, 2011; Norman et al, 2011), physiologically relevant variations in cocaine potency at the DAT do not account for individual differences in cocaine consumption. This suggests that variations in satiety thresholds across animals may be a function of individual differences in the ability of cocaine to elevate serotonin or norepinephrine levels through inhibition of their respective transporters, or possibly other mechanisms or neurotransmitters.
We also found a lack of relationship between $V_{\max }$ of dopamine uptake under drug-free conditions and $P_{\max }$ despite the relationship between cocaine potency and $P_{\max }$. We have reported previously that there is no correlation between $V_{\max }$ and cocaine potency $\left(\mathrm{K}_{\mathrm{m}}\right)$ when assessed using Michaelis-Menten modeling kinetics, as in the current study (Calipari et al, 2015a,b). In a more direct line of evidence, our group and others have shown that upregulation of DAT expression, either through genetic or pharmacologicallyinduced upregulation, does not change cocaine potency as measured by microdialysis, voltammetry, or locomotor activity (Calipari et al, 2013; Salahpour et al, 2008). Although DAT density/uptake is dissociable from cocaine potency, there are many other allosteric changes that can occur in DAT that have been shown to alter cocaine effects with varying effects on orthosteric transporter function. Indeed, cocaine and dopamine bind to partially overlapping segments of the DAT (Huang et al, 2009), and point mutations of the specific sites can alter cocaine potency independently of dopamine uptake (Chen et al, 2005; Chen et $a l, 2006$ ). Cocaine potency can also be modulated by transporter confirmation (outward vs inward or monomer vs oligomer) (Chen and Reith, 2007; Loland et al, 2004; Kohut et al, 2014), or micro-environmental changes in membrane lipids around the DAT (Hong and Amara, 2010). While it is currently unclear what the exact mechanism is for individual differences in cocaine potency that predict high effort responding, our data suggest that these animals differ based on allosteric DAT function independent of uptake rates. This 
is particularly important because it also suggests that cocaine potency, and responding for cocaine, could potentially be altered without affecting the 'normal' function of the DAT, which would allow for therapeutics with limited off-target action.

We show here that cocaine potency at the DAT is positively related to motivation to obtain cocaine in animals with minimal cocaine self-administration experience, however, this relationship appears to be reversed after chronic, high intake cocaine administration. Indeed, following extended access cocaine self-administration protocols, the reinforcing efficacy of cocaine is increased, despite blunted cocaine potency at the DAT (Siciliano et al, 2016; Lack et al, 2008; Calipari et al, 2013; Paterson and Markou, 2003). It is unclear at what point during excessive cocaine use this switch in the relationship between cocaine potency and reinforcing efficacy for cocaine occurs. Further, the precise mechanisms that are recruited to produce high motivation for cocaine despite reduced cocaine potency are not fully understood. One possible mechanism is recruitment of dopamine-dependent glutamatergic plasticity in postsynaptic medium-spiny neuron populations. Indeed, the role of glutamatergic accumbal plasticity in increased cocaine seeking is well documented (Conrad et al, 2008; Pascoli et al, 2014), and the possible reliance of this plasticity on concurrent dopaminergic signaling may explain how motivation for cocaine is increased when potency is attenuated (Cahill et al, 2014; Pascoli et al, 2011).

Together, these data elucidate the neurochemical variations that underlie individual differences in addiction-related cocaine taking behaviors; that is, motivation to administer cocaine, and to respond for sub-threshold doses of cocaine. Further, we outline a novel methodology that allows for the within-session within-subject assessment of discrete motivational states for cocaine as it relates to predicted drug effects occurring throughout the session. This approach provides a tool for relating drug potencies to diverse behavioral outputs while limiting the potential confounds of running repeated behavioral testing across days or subjects. Future work will explore if cocaine actions at other monoamine transporters accounts for variance in consumption of cocaine when price is minimally constraining.

\section{FUNDING AND DISCLOSURE}

The authors declare no conflict of interest.

\section{ACKNOWLEDGMENTS}

This work was funded by NIH grants R01 DA021325, R01 DA030161, P50 DA006634 (SRJ) and F31 DA037710, T32 AA007565, F32 MH111216 (CAS).

\section{REFERENCES}

Ahmed SH, Koob GF (2005). Transition to drug addiction: a negative reinforcement model based on an allostatic decrease in reward function. Psychopharmacology (Berl) 180: 473-490.

Bentzley BS, Fender KM, Aston-Jones G (2013). The behavioral economics of drug self-administration: a review and new analytical approach for within-session procedures. Psychopharmacology (Berl) 226: 113-125.
Bentzley BS, Jhou TC, Aston-Jones G (2014). Economic demand predicts addiction-like behavior and therapeutic efficacy of oxytocin in the rat. Proc Natl Acad Sci USA 111: 11822-11827.

Bock R, Shin JH, Kaplan AR, Dobi A, Markey E, Kramer PF et al (2013). Strengthening the accumbal indirect pathway promotes resilience to compulsive cocaine use. Nat Neurosci. 16: 632-638.

Cahill E, Pascoli V, Trifilieff P, Savoldi D, Kappès V, Lüscher C et al (2014). D1R/GluN1 complexes in the striatum integrate dopamine and glutamate signalling to control synaptic plasticity and cocaine-induced responses. Mol Psychiatry. 19: 1295-1304.

Calipari ES, Ferris MJ, Salahpour A, Caron MG, Jones SR (2013). Methylphenidate amplifies the potency and reinforcing effects of amphetamines by increasing dopamine transporter expression. Nat Commun 4: 2720.

Calipari ES, Ferris MJ, Siciliano CA, Jones SR (2015b). Differential influence of dopamine transport rate on the potencies of cocaine, amphetamine, and methylphenidate. ACS Chem Neurosci 6: $155-162$.

Calipari ES, Ferris MJ, Zimmer BA, Roberts DC, Jones SR (2013). Temporal pattern of cocaine intake determines tolerance vs sensitization of cocaine effects at the dopamine transporter. Neuropsychopharmacology 38: 2385-2392.

Calipari ES, Ferris MJ, Siciliano CA, Zimmer BA, Jones SR (2014). Intermittent cocaine self-administration produces sensitization of stimulant effects at the dopamine transporter. J Pharmacol Exp Ther 349: 192-198.

Calipari ES, Siciliano CA, Zimmer BA, Jones SR (2015a). Brief intermittent cocaine self-administration and abstinence sensitizes cocaine effects on the dopamine transporter and increases drug seeking. Neuropsychopharmacology 40: 728-735.

Callahan PM, De La Garza R 2nd, Cunningham KA (1997). Mediation of the discriminative stimulus properties of cocaine by mesocorticolimbic dopamine systems. Pharmacol Biochem Behav. 57: 601-607.

Chen N, Reith ME (2007). Substrates and inhibitors display different sensitivity to expression level of the dopamine transporter in heterologously expressing cells. J Neurochem. 101: 377-388.

Chen R, Han DD, Gu HH (2005). A triple mutation in the second transmembrane domain of mouse dopamine transporter markedly decreases sensitivity to cocaine and methylphenidate. J Neurochem. 94: 352-359.

Chen R, Tilley MR, Wei H, Zhou F, Zhou FM, Ching S et al (2006). Abolished cocaine reward in mice with a cocaine-insensitive dopamine transporter. Proc Natl Acad Sci USA 103: 9333-9338.

Christensen C, Silberberg A, Hursh S, Huntsberry M, Riley A. (2008). Essential value of cocaine and food in rats: tests of the exponential model of demand. Psychopharmacology 198: 221-229.

Conrad KL, Tseng KY, Uejima JL, Reimers JM, Heng LJ, Shaham Y et al (2008). Formation of accumbens GluR2-lacking AMPA receptors mediates incubation of cocaine craving. Nature 454: 118-121.

Cunningham KA, Callahan PM (1991). Monoamine reuptake inhibitors enhance the discriminative state induced by cocaine in the rat. Psychopharmacology (Berl) 104: 177-180.

Ehrich JM, Phillips PE, Chavkin C (2014). Kappa opioid receptor activation potentiates the cocaine-induced increase in evoked dopamine release recorded in vivo in the mouse nucleus accumbens. Neuropsychopharmacology 39: 3036-3048.

Ferris MJ, Calipari ES, Yorgason JT, Jones SR (2013). Examining the complex regulation and drug-induced plasticity of dopamine release and uptake using voltammetry in brain slices. ACS Chem Neurosci 4: 693-703.

Hermans A, Keithley RB, Kita JM, Sombers LA, Wightman RM (2008). Dopamine detection with fast-scan cyclic voltammetry used with analog background subtraction. Anal Chem 80: 4040-4048.

Hoffman AF, Spivak CE, Lupica CR (2016). Enhanced dopamine release by dopamine transport inhibitors described by a restricted 
diffusion model and fast-scan cyclic voltammetry. ACS Chem Neurosci 7: 700-709.

Hong WC, Amara SG (2010). Membrane cholesterol modulates the outward facing conformation of the dopamine transporter and alters cocaine binding. J Biol Chem. 285: 32616-32626.

Hotz G, Helm-Estabrooks N (1995). Perseveration. Part I: a review. Brain Inj 9: 151-159.

Huang X, Gu HH, Zhan CG (2009). Mechanism for cocaine blocking the transport of dopamine: insights from molecular modeling and dynamics simulations. J Phys Chem B. 113: 15057-15066

Hursh SR, Silberberg A (2008). Economic demand and essential value. Psychol Rev 115: 186-198.

Hursh SR, Winger G (1995). Normalized demand for drugs and other reinforcers. J Exp Anal Behav 64: 373-384.

Kawa AB, Bentzley BS, Robinson TE (2016). Less is more: prolonged intermittent access cocaine self-administration produces incentive-sensitization and addiction-like behavior. Psychopharmacology (Berl) 233: 3587-3602.

Kohut SJ, Hiranita T, Hong SK, Ebbs AL, Tronci V, Green J et al (2014). Preference for distinct functional conformations of the dopamine transporter alters the relationship between subjective effects of cocaine and stimulation of mesolimbic dopamine. Biol Psychiatry. 76: 802-809.

Lack CM, Jones SR, Roberts DC (2008). Increased breakpoints on a progressive ratio schedule reinforced by IV cocaine are associated with reduced locomotor activation and reduced dopamine efflux in nucleus accumbens shell in rats. Psychopharmacology (Berl) 195: 517-525.

Loland CJ, Grånäs C, Javitch JA, Gether U (2004). Identification of intracellular residues in the dopamine transporter critical for regulation of transporter conformation and cocaine binding. $J$ Biol Chem. 279: 3228-3238.

McGinnis MM, Siciliano CA, Jones SR (2016). Dopamine D3 autoreceptor inhibition enhances cocaine potency at the dopamine transporter. J Neurochem 138: 821-829.

Melia KF, Spealman RD (1991). Pharmacological characterization of the discriminative-stimulus effects of GBR 12909. J Pharmacol Exp Ther. 258: 626-632.

Norman AB, Norman MK, Tabet MR, Tsibulsky VL, Pesce AJ (2011). Competitive dopamine receptor antagonists increase the equiactive cocaine concentration during self-administration. Synapse 65: 404-411.

Oleson EB, Richardson JM, Roberts DC (2011). A novel IV cocaine self-administration procedure in rats: differential effects of dopamine, serotonin, and GABA drug pre-treatments on cocaine consumption and maximal price paid. Psychopharmacology (Berl) 214: $567-577$.

Oleson EB, Roberts DC (2009). Behavioral economic assessment of price and cocaine consumption following self-administration histories that produce escalation of either final ratios or intake. Neuropsychopharmacology 34: 796-804.

Oleson EB, Roberts DC (2012). Cocaine self-administration in rats: threshold procedures. Methods Mol Biol. 829: 303-319.

Paly D, Jatlow P, Van Dyke C, Jeri FR, Byck R (1982). Plasma cocaine concentrations during cocaine paste smoking. Life Sci. 30: 731-738.

Pan HT, Menacherry S, Justice JB Jr. (1991). Differences in the pharmacokinetics of cocaine in naive and cocaineexperienced rats. J Neurochem 56: 1299-1306.

Pascoli V, Besnard A, Hervé D, Pagès C, Heck N, Girault JA et al (2011). Cyclic adenosine monophosphate-independent tyrosine phosphorylation of NR2B mediates cocaine-induced extracellular signal-regulated kinase activation. Biol Psychiatry 69: 218-227.

Pascoli V, Terrier J, Espallergues J, Valjent E, O'Connor EC, Lüscher C (2014). Contrasting forms of cocaine-evoked plasticity control components of relapse. Nature 509: 459-464.

Paterson NE, Markou A (2003). Increased motivation for selfadministered cocaine after escalated cocaine intake. Neuroreport 14: $2229-2232$.
Peoples LL, Kravitz AV, Lynch KG, Cavanaugh DJ (2007). Accumbal neurons that are activated during cocaine self-administration are spared from inhibitory effects of repeated cocaine selfadministration. Neuropsychopharmacology 32: 1141-1158.

Peoples LL, Lynch KG, Lesnock J, Gangadhar N (2004). Accumbal neural responses during the initiation and maintenance of intravenous cocaine self-administration. J Neurophysiol 91: 314-323.

Pettit HO, Justice JB Jr (1989). Dopamine in the nucleus accumbens during cocaine self-administration as studied by in vivo microdialysis. Pharmacol Biochem Behav. 34: 899-904.

Porter-Stransky KA, Bentzley BS, Aston-Jones G (2015). Individual differences in orexin-I receptor modulation of motivation for the opioid remifentanil. Addict Biol (e-pub ahead of print).

Richardson NR, Roberts DC (1996). Progressive ratio schedules in drug self-administration studies in rats: a method to evaluate reinforcing efficacy. J Neurosci Methods 66: 1-11.

Ritz MC, Lamb RJ, Goldberg SR, Kuhar MJ (1987). Cocaine receptors on dopamine transporters are related to selfadministration of cocaine. Science 237: 1219-1223.

Roberts DC, Corcoran ME, Fibiger HC (1977). On the role of ascending catecholaminergic systems in intravenous selfadministration of cocaine. Pharmacol Biochem Behav 6: 615-620.

Salahpour A, Ramsey AJ, Medvedev IO, Kile B, Sotnikova TD, Holmstrand E et al (2008). Increased amphetamine-induced hyperactivity and reward in mice overexpressing the dopamine transporter. Proc Natl Acad Sci USA 105: 4405-4410.

Siciliano CA, Calipari ES, Ferris MJ, Jones SR (2014a). Biphasic mechanisms of amphetamine action at the dopamine terminal. $J$ Neurosci 34: 5575-5582.

Siciliano CA, Calipari ES, Ferris MJ, Jones SR (2015a). Adaptations of presynaptic dopamine terminals induced by psychostimulant self-administration. ACS Chem Neurosci 6: 27-36.

Siciliano CA, Calipari ES, Jones SR (2014b). Amphetamine potency varies with dopamine uptake rate across striatal subregions. J Neurochem. 131: 348-355.

Siciliano CA, Ferris MJ, Jones SR (2015b). Cocaine selfadministration disrupts mesolimbic dopamine circuit function and attenuates dopaminergic responsiveness to cocaine. Eur J Neurosci. 42: 2091-2096.

Siciliano A, Fordahl SC, Jones SR (2016). Cocaine self-administration produces long-lasting alterations in dopamine transporter responses to cocaine. J Neurosci 36: 7807-7816.

Stuber GD, Roitman MF, Phillips PE, Carelli RM, Wightman RM (2005a). Rapid dopamine signaling in the nucleus accumbens during contingent and noncontingent cocaine administration. Neuropsychopharmacology 30: 853-863.

Stuber GD, Wightman RM, Carelli RM (2005b). Extinction of cocaine self-administration reveals functionally and temporally distinct dopaminergic signals in the nucleus accumbens. Neuron 46: 661-669.

Suto N, Wise RA (2011). Satiating effects of cocaine are controlled by dopamine actions in the nucleus accumbens core. J Neurosci 31: 17917-17922.

Thomsen M, Han DD, Gu HH, Caine SB (2009). Lack of cocaine self-administration in mice expressing a cocaine-insensitive dopamine transporter. J Pharmacol Exp Ther 331: 204-211.

Tsibulsky VL, Norman AB (1999). Satiety threshold: a quantitative model of maintained cocaine self-administration. Brain Res. 839: 85-93.

Venton BJ, Seipel AT, Phillips PE, Wetsel WC, Gitler D, Greengard $\mathrm{P}$ et al (2006). Cocaine increases dopamine release by mobilization of a synapsin-dependent reserve pool. J Neurosci 26: 3206-3209.

Volkow ND, Wang GJ, Fischman MW, Foltin RW, Fowler JS, Abumrad NN et al (1997). Relationship between subjective effects of cocaine and dopamine transporter occupancy. Nature 386: $827-830$. 
Wise RA, Newton P, Leeb K, Burnette B, Pocock D, Justice JB Jr. (1995). Fluctuations in nucleus accumbens dopamine concentration during intravenous cocaine self-administration in rats. Psychopharmacology (Berl) 120: 10-20.

Wood DM, Emmett-Oglesby MW (1989). Mediation in the nucleus accumbens of the discriminative stimulus produced by cocaine. Pharmacol Biochem Behav 33: 453-457.

Yorgason JT, España RA, Jones SR (2011). Demon voltammetry and analysis software: analysis of cocaine-induced alterations in dopamine signaling using multiple kinetic measures. J Neurosci Methods 202: 158-164.

Zimmer BA, Oleson EB, Roberts DCS (2012). The motivation to self-administer is increased after a history of spiking brain levels of cocaine. Neuropsychopharmacology 37: 1901-1910.

Zittel-Lazarini A, Cador M, Ahmed SH (2007). A critical transition in cocaine self-administration: behavioral and neurobiological implications. Psychopharmacology (Berl) 192: 337-346.

Supplementary Information accompanies the paper on the Neuropsychopharmacology website (http://www.nature.com/npp) 